\title{
Caracterização de pequenas unidades produtoras de leite na região Centro e Noroeste do estado do Rio de Janeiro
}

\section{Characterization of small milk-producing units in the Central and Northwest of the state of Rio de Janeiro}

\author{
Marcio Reis Pereira de Sousa, ${ }^{*}$ Andréa Matta Ristow, ${ }^{*}$ Eduardo Bruno Nogueira, ${ }^{* *}$ Rodolpho de Almeida Torres Filho, ${ }^{* *}$ \\ Marco Antonio Sloboda Cortez ${ }^{* * * *}$
}

\begin{abstract}
Resumo
O estado do Rio de Janeiro possui uma grande quantidade de produtores de leite que produzem menos de 150 litros/dia. Esses produtores apresentam reduzida autonomia na condução do processo produtivo, e limitações quanto à possibilidade de investimentos, uma vez que operam com retornos muito reduzidos para permitir a capitalização de suas unidades de produção. O objetivo deste trabalho foi caracterizar a produção do leite em pequenas unidades produtoras do estado do Rio de Janeiro, para um melhor entendimento dos problemas vivenciados e verificar as condições de obtenção. O trabalho foi desenvolvido nas regiões Noroeste e Centro do estado entre fevereiro e setembro de 2009 . Foram entrevistados 122 pequenos produtores sobre questões socioeconômicas, culturais e tópicos em relação aos procedimentos operacionais da cadeia produtiva do leite. Os resultados foram avaliados por frequência, sendo o efeito das regiões avaliado por teste de Qui-quadrado considerando um nível de significância de $5 \%(P<0,05)$. Os resultados evidenciaram a necessidade de maior comprometimento com a melhoria da qualidade do leite cru relacionados com a higiene de ordenha, assim como a sensibilização dos produtores para a importância de controles de produção e sanitários mais eficientes, além da necessidade de capacitação das pessoas envolvidas com a atividade leiteira.
\end{abstract}

Palavras-chave: pequeno produtor, ordenha, higiene, qualidade.

\begin{abstract}
The state of Rio de Janeiro has a large amount of milk producers that manufacture less than 150 liters/day. These producers have limited autonomy in the flow of the production process, and limitations regarding the possibility of investments, since they operate with very low profit to allow the capitalization of their production units. The goal of this study was to characterize the production of milk in small production units in the state of Rio de Janeiro, for a better understanding of the problems experienced and verify the conditions of the production itself. The study was conducted in the northwest and central regions of the state between February and September 2009. 122 small producers were interviewed about socioeconomic and cultural issues, and topics related to the operational procedures of the milk production chain. The results were evaluated by frequency, and the effect of the regions evaluated by chi-square test at $5 \%$ probability. The results highlighted the need for greater commitment to improving the quality of raw milk related to milking hygiene, as well as the awareness of producers about the importance of more efficient sanitary and production controls, next to the need for empowerment of people involved with the milking activity.
\end{abstract}

Keywords: family agriculture, milking, hygiene, quality.

\section{Introdução}

O Brasil possui mais de 1,5 milhão de produtores de leite. Pelo menos $70 \%$ deste montante são produtores que encontram dificuldades de se manter no setor por não conseguirem pagar os custos envolvidos na atividade. Muitas vezes estes custos estão relacionados com o elevado montante de capital imobilizado na atividade em relação ao nível de produção do estabelecimento (Rodrigues et al., 2009).

\footnotetext{
* Programa de Pós-Graduação em Medicina Veterinária (Doutorado) - Higiene Veterinária e Processamento Tecnológico de Produtos de Origem Animal - Faculdade de Veterinária - Universidade Federal Fluminense. Autor para correspondência. E-mail: marcioreis1@gmail.com

** Programa de Pós-Graduação em Medicina Veterinária (Mestrado) - Higiene Veterinária e Processamento Tecnológico de Produtos de Origem Animal - Faculdade de Veterinária - Universidade Federal Fluminense.

*** Departamento de Zootecnia da Faculdade de Veterinária da Universidade Federal Fluminense.

*** Departamento de Tecnologia dos Alimentos da Faculdade de Veterinária da Universidade Federal Fluminense. Rua Vital Brazil Filho, 64. Niterói - RJ. CEP 24230-340.
} 
No estado do Rio de Janeiro, cerca de $80 \%$ dos produtores destinam o leite produzido para a venda, sendo $62 \%$ formado por pequenos produtores e que produzem menos de 50 litros de leite/dia. A produtividade dos produtores maiores é considerada alta e a dos pequenos, baixa. O pequeno volume obtido pela maioria dos produtores, à exceção dos que produziam acima de 400 litros por dia, contribuía para piorar os indicadores de eficiência técnica e aumentar os custos fixos por litro (FAERJ/SEBRAE, 2010).

Silva e Marafon (2004) verificaram que os pequenos proprietários, que são bastante numerosos no estado do Rio de Janeiro, têm poucas possibilidades de realizar investimentos em suas terras, uma vez que operam com retornos muito reduzidos para permitir a capitalização de suas unidades de produção. Esse é o caso dos pequenos proprietários fornecedores de leite às Cooperativas do Noroeste Fluminense, os quais, embora detenham a propriedade da terra, têm uma forma de inserção na produção regional que implica reduzida autonomia na condução do processo produtivo e limitações quanto à possibilidade de investir em suas unidades de exploração.

Segundo FAERJ/SEBRAE (2010), o desempenho da produção de leite no estado do Rio de Janeiro, de 2002 a 2008, deixou muito a desejar com variação de $6,30 \%$ nos anos extremos e taxa média de crescimento de $1,02 \%$ ao ano.

A caracterização do perfil dos produtores com menor contribuição na produção de leite (pequenos produtores) nas duas regiões do estado do Rio de Janeiro abordadas e de suas respectivas unidades de produção, assim como a verificação das condições higiênico-sanitárias de obtenção, armazenamento e transporte do leite, visa a realização de um diagnóstico sobre os principais fatores que determinam possíveis desvios da produção e na qualidade do leite de acordo com os conceitos de Boas Práticas Agropecuárias determinados nas normas vigentes no país.

\section{Material e métodos}

O trabalho foi desenvolvido nas regiões Noroeste e Centro do estado do Rio de Janeiro no período de fevereiro a setembro de 2009. Foram identificados, a partir dos dados, do relatório sobre os municípios com maior contribuição na produção de leite do estado do Rio de Janeiro no ano de 2007, da empresa de assistência técnica e extensão rural do estado do Rio de Janeiro (EMATER-RJ), a distribuição de produtores e a contribuição em volume de produção de leite entre os municípios e regiões no estado do Rio de Janeiro. Com o intuito de representar cada região, foram entrevistados $10 \%$ dos pequenos produtores de cada região, sendo este percentual definido em função das questões operacionais, técnicas, viabilidade de acesso aos produtores e às fazendas, prazos preestabelecidos para a execução do trabalho, custos, infraestrutura e recursos humanos para a realização do mesmo em relação à determinação de todos os parâmetros a serem analisados. Desta forma, foram preenchidos 80 questionários na região Noroeste e 42 na região Centro, totalizando 122 entrevistas a pequenos produtores e/ou produtores familiares. As perguntas contemplavam os principais pontos socioeconômicos e culturais, sendo utilizado como referência SEBRAE/FAERJ (2003) e FAEMG (2006). Foram também abordados itens relativos à sanidade animal, produção, propriedade, instalações, mão de obra, gestão, higiene de ordenha, armazenamento, transporte, qualidade do leite e os procedimentos operacionais da cadeia produtiva nas fazendas que se relacionassem com a melhoria da qualidade da matéria-prima para produtos de laticínio. Foram utilizados como parâmetros, os padrões da Instrução Normativa ํo 51/ 2002 do Ministério da Agricultura, Pecuária e Abastecimento (MAPA) (BRASIL, 2002) que se relacionavam com a higiene de ordenha, transporte e armazenamento do leite.

Ao final da realização dos questionários foram realizadas análises de frequência das respostas com o intuito de traçar o perfil dos resultados obtidos. O efeito de cada região foi avaliado pelo teste de qui-quadrado considerando um nível de significância de $5 \%(P<0,05)$ no software SAS (Statistical Analysis System V. 6.2-1997).

\section{Resultados e discussão}

\section{Produção e Sanidade Animal}

As propriedades produtoras de leite envolvidas nesta pesquisa apresentaram uma área média de 90,25 hectares na região Centro e 46,82 hectares na região Noroeste. Estes valores, apesar de serem apenas das regiões estudadas, se assemelham às médias do tamanho das propriedades avaliadas por SEBRAE/FAERJ (2003), no Rio de Janeiro, onde a produção de leite ocorreu predominantemente em pequenas propriedades, sendo a área média para o gado de leite de 65 hectares. No experimento citado, foi concluído que para o aumento da produção de leite seria necessário o aumento da produtividade, visto que o crescimento do modelo extensivo se torna inviável.

Aproximadamente metade de todos os rebanhos avaliados era composto por vacas em lactação. Entretanto, houve diferença $(p<0,05)$ entre as regiões que apresentaram, em média, 49 vacas no total e apenas 25 em lactação na região Centro e na região Noroeste um total de 62 vacas e apenas 30 animais em lactação.

Estes dados indicam a falta de orientação e de manejo adequado, resultando em baixa produtividade e alto custo na produção para os pequenos produtores.

Segundo FAEMG (2006), o recomendado é que vacas em lactação sejam de $83 \%$ em relação ao total do rebanho, uma vez que reduzido número de vacas em lactação compromete a lucratividade da empresa.

No geral, $81,03 \%$ dos produtores não recebiam qualquer benefício caso o leite apresentasse melhor qualidade higiênico-sanitária, em sua composição ou quantidade. Entretanto, houve diferença $(p<0,05)$ entre as regiões, sendo que na região Centro, 92,86\% dos produtores não recebiam por meIhor qualidade enquanto na região Noroeste foram $74,32 \%$.

Valores diferentes foram encontrados por FAERJ/SEBRAE (2010) que quanto a bonificação por qualidade do leite, 55\% dos laticínios adotavam esta prática.

É importante que a empresa captadora do leite possua uma política de qualidade que não seja insuficiente e que esta política se traduza num programa de bonificação à qualidade do leite para fins de pagamento (Sousa, 2005). 
Quanto ao tipo de alimentação adotado para o rebanho, muitas vezes as propriedades utilizavam mais de um tipo de prática. Em $67,21 \%$ das propriedades os animais eram criados a pasto. Apenas $22,13 \%$ dos produtores faziam suplementação com sal mineral. Em 48,36\% das propriedades era utilizada a cana-de-açúcar e em 32,79\% utilizavam capineira. O fornecimento de concentrados era feito apenas para $15,57 \%$ dos rebanhos e a silagem utilizada por $9,02 \%$. O sal comum $(\mathrm{NaCl})$ era utilizado por $4,92 \%$ dos produtores.

O controle dos animais, por meio de ficha individual, com os dados produtivo e zootécnicos de cada animal era feita em apenas $25,23 \%$ e a separação dos animais por lote de produção no momento da ordenha era feita apenas em $34,95 \%$ das propriedades.

Em relação ao controle sanitário dos animais, em 91,80\% das propriedades era utilizando carrapaticida e/ou bernicida. Os animais eram vacinados em $82,79 \%$ dos casos. Quanto à vacinação, eram aplicadas vacinas contra febre aftosa, brucelose e paratifo, respectivamente em 95,90; 69,67; e $11,48 \%$ das propriedades. As vacinas que apresentaram diferença entre as regiões $(p<0,05)$ e os respectivos índices de utilização foram: raiva na região Centro, com 85,71\%, na região Noroeste, com 97,50\%; carbúnculo, na região Centro, com $35,71 \%$, e na região Noroeste com $65,00 \%$.

As medidas sanitárias de controle periódico eram feitas para brucelose em $89,34 \%$ das propriedades e para tuberculose em $81,15 \%$, índice que pode ser considerado baixo, se for considerada a obrigatoriedade de vacinação pelo MAPA, pelo Programa Nacional de Controle e Erradicação da Brucelose e Tuberculose (BRASIL, 2006).

Apenas $42,62 \%$ dos produtores faziam algum tipo de controle para monitoramento de casos de mastite, demonstrando o reduzido número de proprietários rurais que estão conscientizados com a produção de um leite de qualidade e com a sanidade do úbere. A baixa taxa de utilização de métodos de monitoramento e controle da mastite encontrada nos resultados desta pesquisa demonstra a necessidade de uma ampla divulgação de informações sobre os benefícios econômicos e sanitários que envolvem a produção do leite.

Em 51,35\% dos locais de produção não era realizada a linha de ordenha.

Esse procedimento apresenta resultados benéficos na redução da transmissão de microrganismos relacionados à mastite (Philpot; Nickerson, 2001; Cortez; Cortez, 2008).

A limpeza dos tetos dos animais a serem ordenhados era realizada, porém foram encontradas diferenças $(p<0,05)$ entre a região Centro, que apresentou $51,61 \%$, e a região Noroeste, com $71,83 \%$ de frequência quanto à execução.

Em todas as propriedades visitadas o "pré-dipping" não era realizado e o "pós-dipping" era feito em 56,73\%. A secagem dos tetos após a limpeza não era realizada em $42,86 \%$ das propriedades.

A qualidade do leite cru é influenciada diretamente pelas condições de higiene na ordenha e armazenamento, bem como sanidade dos animais. As boas práticas de produção aplicadas na produção de leite cru são eficazes para reduzir o nível de contaminação em pontos específicos da linha de ordenha, como teteiras de ordenhadeiras mecânicas e superfície de tetos dos animais em lactação, contribuindo para a melhoraria da qualidade do leite(Yamazi et al, 2010).

O teste da caneca telada de fundo preto, apesar de ser uma forma simples de diagnóstico para mastite (Cortez; cortez, 2008 ), não era realizado em $83,33 \%$ das propriedades na região Noroeste e em $58,97 \%$ na região Centro.

Dados semelhantes foram encontrados por FAERJ/SEBRAE (2010), onde apenas 14\% dos entrevistados disseram que utilizam a caneca de fundo preto para identificar a presença de mastite.

O teste do "California Mastit Test" (CMT) para detecção da ocorrência de mastite, não era realizado em $85,32 \%$ das propriedades, sendo executado em apenas $5,5 \%$ dos casos antes de todas as ordenhas e em $9,17 \%$, somente uma vez ao mês ou quando existia suspeita de mastite nos animais em produção.

A incidência de mastite clínica e subclínica varia de acordo com o grau de higiene e tecnificação da produção de leite. 0 desenvolvimento de técnicas adequadas de manejo de ordenha, controle de mastites e de nutrição é fundamental para a normalização da contagem de células somáticas do leite do tanque, bem como para evitar novos casos (Guilloux, 2007).

Em um experimento realizado por Pelegrino et al., 2008 relataram que a mastite continua sendo um dos principais problemas para a pecuária leiteira, tendo em vista os graves prejuízos acarretados, quer seja pela diminuição da produção ou pela perda dos tetos afetados, demonstrando a importância que devemos dar a prevenção e controle. A escolha de um eficiente método de diagnóstico e a contagem de células somáticas é essencial nesta tarefa.

A introdução de um correto manejo de ordenha é de extrema importância para o controle da mastite, independentemente do tipo de equipamento utilizado e do tamanho do rebanho. A conscientização por parte dos produtores com relação aos prejuízos causados pela doença, a adoção das medidas preventivas e de controle fará com que a enfermidade não afete economicamente sua produção (Silva e Nogueira,2010).

O leite de animais com mastite era descartado em 73,21\% das propriedades, fornecido aos bezerros em 18,75\% dos casos e entregue a cooperativa em 8,04\%. Entretanto, de acordo com Fonseca e Santos (2001), a mastite determina uma série de alterações na produção, composição e nas características físico-químicas do leite, sendo o controle da mastite um dos principais fatores que precisam ser levados em consideração quando se deseja produzir um leite de alto padrão de qualidade e aceitação. No controle desta enfermidade é fundamental o entendimento de que a mastite é mais que uma doença: é o reflexo de um ciclo de ações errôneas e malsucedidas que culminam na enfermidade do animal, e que podem afetar todo o rebanho (Cortez; Cortez, 2008).

\section{Produtor e gestão agropecuária}

De acordo com os dados obtidos, em $86,78 \%$ das propriedades a atividade leiteira era a principal fonte de renda. 
No Brasil, 13,3\% dos agricultores familiares têm na atividade leiteira sua principal fonte de renda. Na região Sudeste, entre as atividades rurais, a pecuária leiteira é a principal e mais importante (Madalena et al., 2001).

O tempo que o ordenhador trabalhava na produção de leite era acima de 10 anos em $72,73 \%$ dos casos; entre 5 e 10 anos em 9,92\%; entre 1 e 5 anos em 12,40\% e a menos de 1 ano em 4,96\% das propriedades. Estes resultados demonstraram um reduzido índice de renovação de funcionários que estariam participando da atividade entre 1 e 5 anos, porém pode indicar a presença de funcionários com uma melhor prática no manejo da ordenha.

Em todas as propriedades que participaram desta pesquisa, todo o leite produzido era destinado à venda para estabelecimentos industriais e/ou cooperativas, sendo o seu transporte realizado por meio de caminhões-tanque em $82,65 \%$ das coletas.

A relação de trabalho com o tipo de mão de obra utilizada na ordenha era caracterizada por contratada em 50,00\% dos casos. Diferenças $(p<0,05)$ foram encontradas e a região Centro apresentou 73,17\% contratada; $14,63 \%$ familiar; e, $12,20 \%$ contratada e familiar. Na região Noroeste foram determinadas $37,66 \%$ contratada; $51,95 \%$ familiar; e, $10,39 \%$ contratada e familiar. Resultados semelhantes foram encontrados no estado de Minas Gerais por FAEMEG (2006) que identificou quanto à mão de obra permanente, uma vantagem no percentual da mão de obra contratada $(55,36 \%)$ em relação à familiar $(44,64 \%)$. Foi percebida uma predominância de mão de obra familiar nos estratos de menor produção e da contratada, nos de maior produção.

Segundo SEBRAE/FAERJ (2010), 64\% correspondem à mão de obra contratada e $36 \%$, à familiar, questionando-se, com base nesses dados, o fato de a atividade leiteira no Rio de Janeiro ser conduzida, basicamente, com mão de obra familiar.

Foi detectado que $60,67 \%$ dos entrevistados nas regiões estudadas utilizavam a forma de contratação por carteira de trabalho assinada. Já no trabalho realizado por SEBRAE/ FAERJ em 2003, verificou-se que em todo o estado do Rio de Janeiro foram encontradas baixas frequências de empregados com carteira assinada em produtores de leite no estrato de produção de até 50 litros/dia, sendo de apenas $50 \%$, enquanto produtores acima de 400 litros assinavam carteira de trabalho de seus empregados em $83 \%$ dos casos.

Em média, 55,93\% das propriedades não possuíam funcionário exclusivo para a atividade de ordenha, sendo encontradas diferenças $(p<0,05)$ entre as regiões e na região Noroeste não apresentava funcionário exclusivo em 49,35\% enquanto na região Centro foram 68,29\%.

Em apenas $24,78 \%$ das propriedades, o ordenhador recebia algum tipo de incentivo ou bonificação pelo bom trabalho realizado, o que se realizado, pode representar um estímulo para a produção com qualidade.

O nível de escolaridade do responsável pela ordenha foi representado pelo ensino fundamental incompleto em $55,08 \%$ das respostas, ensino fundamental completo em $12,71 \%$ e analfabeto em $12,71 \%$ dos casos. Os demais níveis de escolaridade somaram 19,5\%. O baixo nível de escolaridade pode refletir no conhecimento sobre a atividade leiteira e dificultar um melhor aproveitamento e qualificação em programas de treinamento e transferência de tecnologia.

A participação dos funcionários em atividades de treinamento relativas à ordenha foi realizada apenas por 30,51\%. Entre as principais fontes de informação sobre leite a assistência prestada pela Cooperativa foi considerada pelos produtores entrevistados a de maior importância.

\section{Ordenha higiênica e transporte}

A distância entre as propriedades produtoras e o estabelecimento beneficiador do leite estavam a menos de $25 \mathrm{~km}$ em $66,38 \%$. Em $65,69 \%$ das propriedades pesquisadas 0 tempo entre o armazenamento e a coleta do leite estava em conformidade com a legislação vigente, que estipulou em 48 horas o tempo entre coletas (BRASIL, 2002).

A frequência com que o leite é enviado ao laticínio, de acordo com pesquisa de campo realizada por FAERJ/SEBRAE (2010) é de 2 em 2 dias em 60,5\% das propriedades estudadas.

A distância entre o produtor e o estabelecimento beneficiador talvez tenha determinado a possibilidade de realização das coletas mais frequentes na maior parte das propriedades. Sendo um produto de alta perecibilidade, a proximidade dos produtores ao estabelecimento beneficiador favorece a manutenção da qualidade, facilita a logística de coleta, reduz custos com transporte, diminui o tempo transcorrido entre a ordenha inicial e seu recebimento na indústria.

Houve diferença significativa $(p<0,05)$ entre a região Noroeste com $65,08 \%$ e $66,67 \%$ de conformidade de tempo de coleta da região Centro.

O tempo de entrega do leite não refrigerado foi inferior a duas horas para $92,06 \%$ dos entrevistados, demonstrando o cumprimento das normas e a proximidade dos produtores com os estabelecimentos industriais. Segundo a Instrução Normativa $n^{\circ}$ 51, o leite pode ser entregue à temperatura ambiente em até duas horas após a ordenha, desde que se apresente em conformidade com os requisitos físicoquímicos e microbiológicos determinados (BRASIL, 2002).

O preço foi apontado por $73,04 \%$ dos entrevistados como o principal problema relacionado com a produção de leite. Entretanto, 93,39\% dos produtores pretendiam aumentar ou manter a produção. O cálculo de custo de produção era feito por menos da metade dos produtores, apenas $42,86 \%$. Nenhum controle sobre os custos de produção envolveu $57,14 \%$ dos entrevistados, o que é preocupante, pois demonstrou a necessidade de aprendizagem e de formação profissional e empresarial dos mesmos.

Segundo Marion e Segatti (2006), é necessária uma análise e o desenvolvimento de um sistema de gestão de planejamento e de custos agropecuários para as pequenas propriedades rurais relacionadas com a cadeia produtiva do leite, o que favorece o produtor no mercado interno frente ao cenário econômico atual, destacando sua contribuição na formação de renda e na absorção de mão de obra.

Segundo os resultados das pesquisas, para os produtores, os assuntos com maior dificuldade em se conseguir informações foram: saúde do animal, cuidados de higiene na ordenha e manejo animal. Diferentes resultados foram 
encontrados por SEBRAE/FAERJ (2003), onde as informações mais frequentes recebidas pelos entrevistados de suas pesquisas foi sobre alimentação do rebanho $(47,36 \%)$ e sanidade animal $(28,08 \%)$.

Devido ao pequeno volume de produção leiteira diária, a ordenha manual era utilizada por $77,87 \%$ das propriedades e em $22,13 \%$ dos casos era utilizada a ordenha mecanizada. O local de realização da ordenha era em curral coberto em $90,91 \%$ e apenas $4,96 \%$ era realizado em sala de ordenha. A utilização de estábulo ou curral descoberto foi feita em $4,14 \%$ das propriedades.

Segundo Brasil (2002), o local de ordenha deve ser mantido sob rigorosas condições de higiene.

Em $91,67 \%$ das propriedades era realizada a filtragem do leite após a ordenha, sendo realizada de forma aceitável, com utensílios adequados.

Foi observada uma diferença significativa ente as regiões Centro e Noroeste em relação à temperatura de resfriamento $(p<0,05)$. Na região Centro, temperaturas abaixo de $7^{\circ} \mathrm{C}$ foram detectadas em $50 \%$ das propriedades; já na região Noroeste, esta temperatura foi alcançada em $78,95 \%$ dos casos. $\mathrm{Na}$ média geral entre as duas regiões pesquisadas, temperaturas entre $7^{\circ} \mathrm{C}$ e $10^{\circ} \mathrm{C}$ foram encontradas em $10,53 \%$ das propriedades e acima de $10^{\circ} \mathrm{C}$ em $7,37 \%$ dos casos. O tempo necessário para atingir a temperatura de resfriamento foi inferior a 3 horas em $88,37 \%$. Para o resfriamento, eram utilizados tanques de expansão direta em $68,76 \%$, tanque de imersão em $9,38 \%$ das propriedades e $21,86 \%$ outras formas de resfriamento.

Em pesquisa realizada por FAERJ/SEBRAE (2010), 86\% do resfriamento do leite foi realizado em tanques de expansão e $13 \%$ em tanques de imersão e $1 \%$ outros.

$\mathrm{Na}$ Instrução Normativa oㅡ 51 (BRASIL, 2002), é preconizado que o leite cru refrigerado deve alcançar a temperatura de $7^{\circ} \mathrm{C}$, em até 3 horas após a ordenha.

Na maior parte das propriedades não existiam procedimentos técnicos preestabelecidos de higiene, para o local de ordenha. Diferenças $(p<0,05)$ foram determinadas entre as regiões Centro 73,17\% e 91,03\% na região Noroeste. A baixa utilização de procedimentos de higienização demonstrou falta de capacitação do pessoal envolvido tanto nas operações de higiene de ordenha quanto para os equipamentos e utensílios utilizados na mesma. Tanto procedimentos de higiene relativos ao local, quanto àqueles utilizados antes $e$ depois da ordenha apresentaram frequências muito baixas, assim como pelo fato da limpeza do latão antes de encher com leite não ser realizada em $96,08 \%$ dos casos.

Os procedimentos de limpeza e/ou sanificação do tanque de refrigeração foram realizados após a entrega do leite em

\section{Referências}

BRASIL. Ministério de Agricultura, Pecuária e Abastecimento. Programa Nacional de Controle e Erradicação da Brucelose e da Tuberculose Animal (PNCEBT): Manual técnico. Brasília, 2006. 184 p.

BRASIL. Instrução Normativa ํㅡ. 51, de 20 de setembro de 2002.

CORTEZ, M.A.S.; CORTEZ, N.M.S. Qualidade do leite: boas práticas agropecuárias e ordenha higiênica. Niterói: EdUFF, 2008, 77 p. todas as propriedades, sendo utilizada uma grande variedade de produtos, muitos inadequados para utilização em procedimentos de higienização, evidenciando uma falta de capacitação, conhecimento e dificuldades na obtenção e manutenção de eficiência operacional.

Em uma pesquisa realizada por Sousa (2005), a decisão de uso e compra de produtos de higienização para equipamentos de ordenha era tomada pelo produtor com base em observações, informações e instruções repassadas por vendedores, técnicos ou não, chegando-lhes, por vezes, distorcidas, incompletas, tendenciosas e/ou conflitantes, evidenciando uma necessidade de apoio técnico-científico independente. Neste experimento, foi detectada a demanda de planejamento, desenvolvimento e implementação de uma política instrucional e de capacitação relacionada com a higienização de equipamentos de ordenha.

A ordenha é a etapa da produção leiteira que exige o maior cuidado, devido à forte influência na qualidade do leite. Envolve desde a escolha correta do local onde o animal deverá ser ordenhado até os hábitos de higiene do ordenhador, os cuidados com os animais e higiene dos utensílios. O local de ordenha deve ser cimentado, coberto, arejado, limpo e protegido contra contaminação por poeira ou outras sujeiras do ambiente (Gracindo e Pereira, 2009).

Segundo Fariña et al. (2008), a infraestrutura das propriedades, os hábitos de higiene pessoal, as condições apropriadas de ordenha e de armazenamento do leite podem apresentar melhoria significativa a partir do treinamento e da disseminação de informações entre produtores.

\section{Conclusão}

A cadeia produtora de leite no estado do Rio de Janeiro, especialmente em relação aos pequenos produtores, se caracteriza por ainda apresentar deficiências intrínsecas que comprometem a produtividade e a eficiência em obtenção de leite. A região Noroeste apresentou-se mais desenvolvida e apta para a produção de leite de qualidade do que a região Centro. É necessário melhorar a infraestrutura e disponibilizar informações técnicas. Existe uma evidente necessidade de aprimoramento quanto aos controles na produção, sanidade animal e ordenha higiênica, assim como a profissionalização na atividade leiteira. Existe uma falta de monitoramento e um reduzido comprometimento da qualidade em relação à produção. Os produtores cumpriam o mínimo das exigências relacionadas com a sanidade animal. O leite representou a principal fonte de renda da maioria dos entrevistados. Os pequenos produtores não abandonaram ou têm planos de abandonar a atividade. Não foi detectada nenhuma iniciativa de investimentos em educação e capacitação profissional dos ordenhadores.

FAEMG. Diagnóstico da pecuária leiteira do estado de Minas Gerais em 2005: relatório de pesquisa. Belo Horizonte, 2006.

FAERJ/SEBRAE. Diagnóstico da cadeia produtiva do leite do estado do Rio de Janeiro: Relatório de Pesquisa. Rio de Janeiro: FAERJ: SEBRAE- RJ,2003.

FAERJ/SEBRAE. Diagnóstico da cadeia produtiva do leite do estado do Rio de Janeiro. Rio de Janeiro: FAERJ: SEBRAERJ, 2010. 
FONSECA, L.F.L.; SANTOS,M.V. Qualidade do leite e controle de mastite. São Paulo: Lemos, 2001.175 p.

FARIÑA,L.O.; FALCONI,F.A.; BULHÕES,R.; IARK,A.C.; TESSARO,A.B.; SALVATTI,F.; TAVARES,J.A.; CORRÊA,J.M.; SOSA,D.E.F.; FERREIRA,R.; TORRES,E.F. Avaliação das condições higiênicosanitárias em estabelecimentos da agricultura familiar envolvidos na pecuária leiteira dos municípios de Cascavel e Guaraniaçu/PR. Revista Conexão UEPG, 4. ed., 2008.

GRACINDO, A.P.A.C.;PEREIRA,G.F. Produzindo leite de alta qualidade. Natal, RN: EMPARN, 2009.

GUILLOUX A.G.A., CARDOSO M.R.I., CORBELLINI L.G. Análise epidemiológica de um surto de mastite bovina em uma propriedade leiteira no estado do Rio Grande do Sul. Acta Scientiae Veterinariae, 2007.

MADALENA, F.E.; MATOS,L.L; JÚNIOR, E.V.H. Produção de leite e sociedade: uma análise crítica da cadeia do leite no Brasil. Belo Horizonte: FEPMVZ, 2001.

MARION, J C; SEGATTI, S. Sistema de Gestão de Custos nas Pequenas Propriedades Leiteiras. Custos e @gronegócio on line, v. 2, n. 2 - jul/ dez, 2006.

MICROSOFT® OFFICE EXCEL. Microsoft Office Professional Edição 2003. Copyright (C) 1985-2003 Microsoft Corporation. 2003.

PELEGRINO, R.C.;MELLO, F.C.;AMARAL, G.A.C.;PINTO,E.A.T. Mastite em vacas leiteiras. Revista Científica Eletrônica de Medicina Veterinária, ano VI, n. 10, janeiro 2008.

PHILPOT, W.N.; NICKERSON, S. C. Vencendo a luta contra a mastite. São Paulo: Milkbizz/Westfalia Surge, 2002, 192 p.
RODRIGUES, M.H.S.; MULLER ,C.A.S.; SOUZA, M.P.; Eficiência na produção de leite das pequenas propriedades do município de Jaru. XLI, SBPO, 2009. Pesquisa Operacional na Gestão do Conhecimento, p. 2327.

SAS INSTITUTE. SAS/STAT software: changes and enhancements through release 6.12. Cary: Statistical Analysis System Institute, 1997. $1167 \mathrm{p}$.

SCHMITZ, H.; MOTA, D.M. Agricultura familiar: elementos teóricos e empíricos. Itabuna, Revista Agrotrópica. v. 19, p. 21-30, 2007.

SILVA, E.S.O.; MARAFON, G.J. A agricultura familiar no estado do Rio de Janeiro. II Seminário Internacional sobre Desenvolvimento Regional Programa de Pós-Graduação em Desenvolvimento Regional Mestrado e Doutorado Santa Cruz do Sul, RS - Brasil - 2004.

SILVA, M.V.M.;NOGUEIRA, J. L., Mastite: controle e profilaxia no rebanho bovino. Revista científica eletrônica de medicina veterinária, ano VIII, n. 15, julho 2010.

SOUSA, M.R.P. Higienização de equipamentos de ordenha mecanizada canalizada: diagnóstico de procedimentos tecnológicos, Seropédica: UFRRJ, 2005, 85 p. Dissertação-(Mestrado em Ciência e Tecnologia de Alimentos). Universidade Federal Rural do Rio de Janeiro. 2005

YAMAZI,A.K.; MORAES,P.M.; VIÇOSA G.N.; ORTOLANI M.B.T.; NERO L.A.; Práticas de produção aplicadas no controle de contaminação microbiana na produção de leite cru. Uberlândia, Biosci. J., v. 26, n. 4, p. 610-618, July/Aug. 2010. 